University of Louisville

ThinkIR: The University of Louisville's Institutional Repository

Electronic Theses and Dissertations

$7-2018$

\title{
The effectiveness of localized ultrasound and aptamer surface modification on nanoemulsions for drug delivery to spheroids.
}

Daniel A. Hodge

University of Louisville

Follow this and additional works at: https://ir.library.louisville.edu/etd

Part of the Nanoscience and Nanotechnology Commons, and the Other Biomedical Engineering and Bioengineering Commons

\section{Recommended Citation}

Hodge, Daniel A., "The effectiveness of localized ultrasound and aptamer surface modification on nanoemulsions for drug delivery to spheroids." (2018). Electronic Theses and Dissertations. Paper 3004. https://doi.org/10.18297/etd/3004

This Master's Thesis is brought to you for free and open access by ThinkIR: The University of Louisville's Institutional Repository. It has been accepted for inclusion in Electronic Theses and Dissertations by an authorized administrator of ThinkIR: The University of Louisville's Institutional Repository. This title appears here courtesy of the author, who has retained all other copyrights. For more information, please contact thinkir@louisville.edu. 


\title{
THE EFFECTIVENESS OF LOCALIZED ULTRASOUND AND APTAMER SURFACE MODIFICATION ON NANOEMULSIONS FOR DRUG DELIVERY TO SPHEROIDS
}

By

\author{
Daniel A. Hodge
}

Bachelor of Bioengineering, University of Louisville, 2017

\author{
A Thesis \\ Submitted to the Faculty of the \\ University of Louisville \\ J. B. Speed School of Engineering \\ as Partial Fulfillment of the Requirements \\ for the Professional Degree
}

MASTER OF ENGINEERING

Department of Bioengineering

May 2018 


\section{THE EFFECTIVENESS OF LOCALIZED ULTRASOUND AND APTAMER SURFACE MODIFICATION ON NANOEMULSIONS FOR DRUG DELIVERY TO SPHEROIDS}

Submitted by:

Daniel A. Hodge

A Thesis Approved On

(Date)

by the Following Reading and Examination Committee:

Jonathon Kopechek, Ph.D, Thesis Director

Jill Steinbach-Rankins, Ph.D

Ayman El-Baz, Ph.D

Paula Bates, Ph.D 


\title{
ACKNOWLEDGMENTS
}

I would like to thank all the fellow scientists working in the research laboratory of Dr. Jonathan Kopechek for helping me with some of the lab work in this project, for teaching me how to operate the machinery required to perform the lab work, and for answering questions and providing feedback.

\author{
Dr. Jonathan Kopechek \\ Connor Centner \\ Emily Murphy \\ Mariah Priddy
}




\begin{abstract}
Cancer is a group of diseases that affects 1.6 million and kills nearly 600,000 Americans each year. The National Cancer Institute defines it as "diseases in which abnormal cells divide without control and can invade nearby tissues" and it is often treated with one or more of the following: chemotherapy, radiation, surgery. The expense for these treatments is expected to rise to $\$ 156$ billion by 2020 . Localized delivery can improve effectiveness and cancer survival rates, decrease the cost of treatment, and decrease the side effects of chemotherapy. This paper addresses models for this localized delivery through nanoemulsions. Nanoemulsions are a spherical layer of a hydrophobic substance holding and surrounded by hydrophilic substances or a spherical layer of a hydrophilic substance surrounded by and holding hydrophobic substances with a diameter less than one micrometer. Nanoemulsions are in development for cancer treatment due to their thermodynamic stability, which improves shelf-life.

While nanoemulsions on their own do not provide specific targeting, two potential options for targeted and local delivery are addressed here. This paper explores the effect of AS1411, an aptamer which can target some cancer cells, on nanoemulsions for chemotherapy delivery. AS1411 binds to nucleolin, which is overexpressed in many cancer cells and appears on their surface, allowing AS1411 to target them. AS1411 also has the ability to inhibit cancer cell functions and kill cancer cells selectively. When taken into healthy cells, AS1411 is removed through exocytosis or efflux instead of damaging them. Using AS1411 on nanoemulsions should cause the cancerous cells to actively absorb the nanodroplets while limiting uptake by healthy cells.
\end{abstract}

Ultrasound-induced vaporization is also explored as a way to cause nanoemulsions to release their payload into cancer cells. Vaporization of the nanoemulsion droplets weakens surrounding membranes and forces drugs out of nanoemulsions as microjets. This method can be used on many cancers, especially those near to the skin as there is less interference. One caveat is that ultrasound may not be safe for lung cancer treatments, as ultrasound cannot penetrate air in the lungs and the reflected waves may damage healthy lung tissue. These additions to systemic nanoemulsion treatment, both combined and separate, are tested on both traditional single-layer 
MDA-MB-231 breast cancer cells and on artificially grown tumors, called spheroids. This spheroid testing allows for a look into how these treatments may be affected by avascular tumors, which are more drug resistant than normal cancer.

To test the effects of these treatment options, FITC-labeled or doxorubicin-loaded nanoemulsions were produced and applied on top of the cancerous cells. Doxorubicin was used due to its chemotherapeutic properties and its lack of interference with MTT assay readings. Some samples were created with AS1411 covalently bound to the outside while others were created with no payload or targeting to act as a control. After a period of incubation the nanoemulsions in some samples are ultrasonicated while others remain untouched as control. Following further incubation, the cells were harvested and assayed for analysis, using flow cytometry for FITC detection and an MTT assay for doxorubicin-induced cytotoxicity detection.

The results of these tests showed that ultrasound improved cytotoxicity in doxorubicintreated spheroids but worsened FITC uptake. This reduced FITC uptake may be caused by holes in the cell membrane induced by ultrasound, allowing FITC to leak back out of the cells. AS1411, both with and without ultrasound, had an insignificant effect on cytotoxicity in this study. The lack of consistent improvement by AS1411 may be due to the use of cancerous cells exclusively in our spheroids, which result in all of the nanoemulsions releasing their payloads onto the cancer regardless of whether or not they bind to their nucleolin. Another theory is that the incubation times were too long, so the passive uptake of the nanoemulsions was able to overshadow to the active uptake stimulated by AS1411. The results of this research encourage further study into the potential efficacy of these treatment options. 


\section{TABLE OF CONTENTS}

APPROVAL PAGE




\section{NOMENCLATURE}

Spheroid $=$ An artificially grown tumor in a nearly spherical shape.

Nanoemulsion $=$ A drop of oil in water or a drop of water in oil ranging between 20 and $200 \mathrm{~nm}$.

AS1411 = A chain of DNA that reads 5'-GGTGGTGGTGGTTGTGGTGGTGGTGG-3'. It has been shown to have both anti-cancer and cancer targeting properties.

Doxorubicin $=\mathrm{A}$ common chemotherapeutic drug used in patients and in research. 


\section{LIST OF FIGURES}

Figure 1: A photo of an MDA-MB-231 spheroid grown in this lab.........................

Figure 2: MTT absorbance vs. doxorubicin concentration and seeding cell density............10

Figure 3: 15k seeded spheroid after 5 days of growth and $50 \mu \mathrm{M}$ doxorubicin (left) and a 15k seeded spheroid after 5 days of growth and no doxorubicin treatment (right) (spheroid plate,

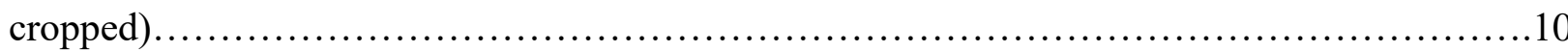

Figure 4: Absorbance of MTT treated spheroids following doxorubicin treatments at different times.

Figure 5: Percent Viability of MDA-MB-231 Cells Following Doxorubicin Treatment..........13

Figure 6: Weekly fluorescence test to determine nanoemulsion lifespan through treatment of flat cells

Figure 7: Percent Viability determined via plate reading for MTT treated (2 hour incubation) spheroids treated with doxorubicin nanoemulsions and ultrasound.... 15

Figure 8: Average plate reading for MTT treated (2 hour incubation) spheroids treated with unsonicated doxorubicin nanoemulsions.

Figure 9: The combined data from Figure 8 and 9. The normalized values of the absorbance from spheroids 16

Figure 10: Absorbance of MTT treated spheroids following doxorubicin treatment. Each emulsion sample contained $10 \mu \mathrm{L}$ of nanoemulsions, with the percentage indicating the amount that contained doxorubicin. Ultrasound occurred 30 minutes following nanoemulsion place.....17

Figure 11: Absorbance of MTT treated spheroids following liquid doxorubicin treatment.......18

Figure 12: Normalized values from Total Cell Association Flow Cytometry MACS Quantity Analyzer reading of FITC in flat cells after various treatments for 1 hour. $(1=3341.7$ cells $)$.....19 
Figure 13: A normalized graph showing the cells counted via Total Cell Association Flow Cytometry MACS Quantity Analyzer containing FITC or Cy5 immediately following ultrasound

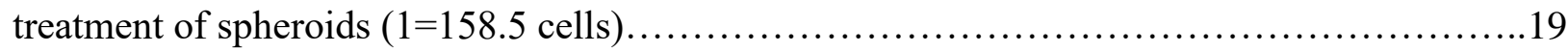

Figure 13: Absorbance of MTT in spheroids following nanoemulsion treatments. The number of blank nanoemulsions in each group is equal to the amount of nanoemulsions at that concentration

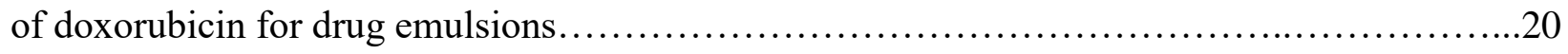

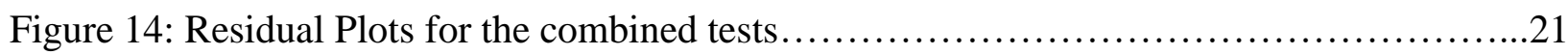




\section{INTRODUCTION}

Cancer is a group of diseases in which body cells grow abnormally and damage other cells. It is a growing global concern and is now responsible for one in every six deaths, making it the second leading cause of death worldwide (WHO). The market for cancer treatment in the United States is growing (NCI) and new treatments are constantly in development. Traditional chemotherapy kills rapidly multiplying cells, which also results in damage to normal tissues, such as bone marrow, hair, and digestive tract tissues (ACS). To enhance the effectiveness of chemotherapy on cancerous cells and limit these side effects, targeted delivery is being researched. This paper addresses adaptations to nanoemulsion delivery to become a targeted therapy.

Nanoemulsions are a type of nanoparticle where a layer of hydrophobic material surrounds a hydrophilic core or a hydrophilic material surrounds a hydrophobic core. These particles can be used as drug vehicles to protect and carry chemotherapies throughout a body. Nanoemulsions are also small enough $(50-200 \mathrm{~nm})$ to pass through leaky vasculature and accumulate in tumors, resulting in higher delivery to cancer cells (Zhou). Ultrasound can be applied to perfluorocarbonbased nanoemulsions and can cause them to vaporize due to the low boiling point of the perfluorocarbon. This process can induce cavitation of the vaporized droplets, which can result in microstreaming and enhance drug delivery to nearby cells whose membranes were permeabilized by the ultrasound (Zhou). While vaporization and cavitation cannot target individual cell types, ultrasound can be focused to an area to specifically vaporize nanoemulsions there, resulting in localized delivery.

AS1411 is an aptamer discovered by Bates et al. which binds to nucleolin. It is 26 nucleotides long and reads 5'-GGTGGTGGTGGTTGTGGTGGTGGTGG. AS1411 is removed via efflux in normal cells, but in cancer cells is absorbed by micropinocytosis and increases in concentration (Bates). AS1411 also binds to nucleolin that appears on the membranes of cancer cells, allowing it to function as a targeting molecule (Luo et al.).

Spheroids are artificially grown tumors. The use of spheroids in these experiments should allow for greater understanding of how these treatments will function in a 3D environment before 
performing in vivo experimentation (Ivascu). Ultrasound cavitation, due to the creation of microjets, should be able to deliver drugs further into spheroids compared to spheroids not treated with ultrasound. Concerns have been raised that this cavitation could break cells off the tumor and induce metastasis, but no tests have been performed yet to verify this concern. If this is also true in vivo, ultrasound should improve the speed at which drugs kill cancer cells and give the cancers less time to metastasize. While AS1411 is not anticipated to have an additional effect on spheroids compared to flat tissue, spheroids should provide a more accurate model of drug delivery for in vivo comparisons. A photo of one spheroid from this lab is presented below as Figure 1.

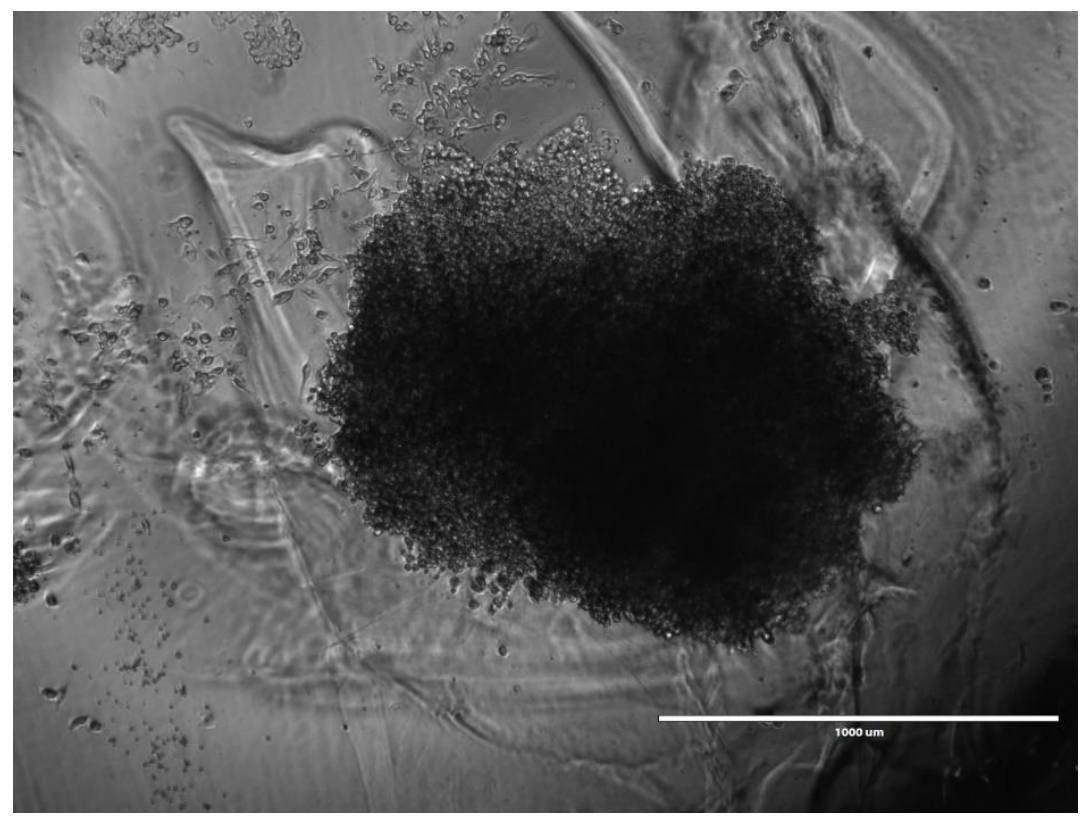

Figure 1: A photo of an MDA-MB-231 spheroid grown in this lab

This project explores how AS1411 and ultrasonication each affect the uptake of chemotherapeutic nanoemulsions into cancer cells in spheroid formations. The uptake of AS1411 into tumors has been tested before using fluorescent compounds, PGG-PTX, which is a nanoparticle-forming chemotherapy drug, and spheroids (Luo, et al.). The use of nanoemulsions to improve drug delivery to spheroids has also been tested, such as in the treatment of human mammary cancer cells with photodynamic therapy (Muehlmann, et al.). This project offers greater insight into how to improve cancer therapies by combining these augmentations to traditional 
therapy and testing the combined treatment against both controls and the two augmentations alone. This is improved by the use of spheroids to simulate the three-dimensional tissue growth of tumors in vivo. 


\section{INSTRUMENTATION AND EQUIPMENT}

Spheroid Production:

Spheroids were produced using MDA-MB-231 human breast carcinoma cells. Additional materials used were Trypsin-EDTA 0.05\% (1 mL Trypsin-EDTA 0.25\%: 4 mL PBS), sterile PBS, deionized (DI) water, Dulbecco's Modified Eagle Medium (DMEM) cell culture media, dry agar powder, autoclave-safe $250 \mathrm{~mL}$ flasks, an autoclave, a microwave, a sterile hood, 24-well and 96well plates, 96-well Corning ultra-low attachment spheroid plates, a hemocytometer, a shaker with speed of at least $120 \mathrm{rpm}$, a centrifuge with speed of at least $1500 \mathrm{rpm}$, pipettes, and pipette tips.

MTT Assay Protocol:

To perform the MTT assay, the following materials were used: MTT solution, lysis buffer, Trypsin-EDTA $0.25 \%$, a plate reader, pipettes, and pipette tips.

\section{Cell Splitting/Harvesting}

To split and harvest cells the following materials were used: 10/25 mL cell flasks, MDA-MB-231 Cells, Trypsin-EDTA $0.25 \%$, Sterile PBS, deionized (DI) Water, Dulbecco's Modified Eagle Medium (DMEM) media, a sterile hood, formaldehyde, pipettes, and pipette tips.

Nanoemulsion Production

To produce nanoemulsions, the following materials were used: Cy5-AS1411 aptamer, AS1411thiol aptamer, Tris(2-carboxyethyl)phosphine (TCEP), sodium phosphate buffer, maleimide lipid, an aspirator, doxorubicin hydrochloride, ice, a centrifuge, a sonicator, an extruder, and 200nm membranes. 


\section{PROCEDURE}

Spheroid Production (Agar Method)

Prepare 1.25\% Agar for coating non-tissue culture treated plates:

An autoclave safe $250 \mathrm{~mL}$ bottle was pre-warmed in a $40{ }^{\circ} \mathrm{C}$ water bath. $90 \mathrm{~mL}$ of deionized $\mathrm{H}_{2} \mathrm{O}$

(DI water) was heated in the $250 \mathrm{~mL}$ bottle to $80-90{ }^{\circ} \mathrm{C}$ using a hot plate. A cap was placed on the flask at this point to prevent evaporation. $1.25 \mathrm{~g}$ of dry agar was added to the bottle and stirred with a glass rod until the lumps disappeared. The total volume of the bottle was raised to $100 \mathrm{~mL}$ by adding DI water while the solution was being heated. The final solution was stirred with a magnetic stir bar until thoroughly mixed. The agar solution, still loosely capped, was autoclaved for 15 minutes at $121{ }^{\circ} \mathrm{C}$ using slow exhaust. The bottle was removed from the autoclave and allowed to cool prior to the cap being tightened. The solution was stored at room temperature.

Agar coating of non-tissue culture treated plates (sterile conditions):

The agar was warmed to its melting point (approximately $70^{\circ} \mathrm{C}$ ) by microwaving it at 30 power for 3 minutes followed by $100 \%$ power for 30 seconds. $200 \mu \mathrm{L}$ (for a 24 -well plate) or $100 \mu \mathrm{L}$ (for a 96-well plate) of the agarose was pipetted into each well of a plate. The agar was pipetted up and down a few times in the hot agar to avoid dripping. The pipetting was done with smooth movement around the well. The tip of the pipet was changed every 12 samples to avoid agar building up and blocking it. The plate was stored at room temperature under sterile condition. After a few hours, the plate was checked to see if the agar had fully solidified, so cells could be plated.

\section{Create spheroids (sterile conditions):}

Human cancer (MDA-MB-231) cells were detached from $80 \%$ confluency using $0.05 \%$ trypsin. The cells were counted and centrifuged at $1500 \mathrm{rpm}$ for 5 minutes in $4{ }^{\circ} \mathrm{C}$. The amount of DMEM required for a final cell concentration of 100,000 cells $/ \mathrm{mL}$ (24-well plate) or 60,000 cells $/ 100 \mu \mathrm{L}$ (96-well plate) was calculated using the cell count. The trypsin was aspirated and the cells were suspended in the amount of DMEM calculated. In the event that far more DMEM was required to 
dilute the cell count than was needed to grow spheroids, some of the cells would be discarded. 1 $\mathrm{mL}$ (24-well plate) or $100 \mu \mathrm{L}$ (96-well plate) of cells and media were pipetted into each well of a round bottom ultra-low attachment plate (Corning Inc., Corning, NY, USA) or an agar treated flat bottom plate created in a previous step. The lid was placed on each plate and the plate was shaken at $120 \mathrm{rpm}$ for 15 minutes to allow for aggregation. The cells were incubated for $37^{\circ} \mathrm{C}$ for 3 to 7 days.

Spheroid treatment and disaggregation:

After the spheroids were formed, various concentrations of treatments were applied to each well after being diluted to $1 \mathrm{~mL}$ per well (24-well plate) or $100 \mu \mathrm{L}$ per well (96-well plate). A negative control (no treatment) and a positive control (all cells are killed) are applied to some wells for comparison. The spheroids are incubated for a set period of time. For 24 -well plates, $1600 \mu \mathrm{L}$ of media was removed from each well using a $200 \mu \mathrm{L}$ pipet eight times and $600 \mu \mathrm{L}$ of fresh trypsin was added to disaggregate the spheroids. For $96-$ well plates, $150 \mu \mathrm{L}$ was removed from each well using a $200 \mu \mathrm{L}$ pipet and $150 \mu \mathrm{L}$ of fresh trypsin was added. The plates were then incubated for at least one more hour before being pipetted 3-5 times to disaggregate the spheroids. Cell viability was measured via MTT Assay.

\section{$\underline{\text { MTT Assay Protocol: }}$}

$0.1 \mathrm{~mL}$ (24-well plate) or $10 \mu \mathrm{L}$ (96-well plate) of $5 \mathrm{mg} / \mathrm{mL}$ stock MTT solution was added to each well. Each well was incubated for 4 hours at $37^{\circ} \mathrm{C}$ before $1 \mathrm{~mL}$ (24-well plate) or $100 \mu \mathrm{L}$ (96-well plate) of lysis buffer was added to each well. The final solution was incubated overnight at $37^{\circ} \mathrm{C}$ and read on a plate reader.

\section{Cell Splitting}

The source flask was examined under a microscope and the confluency of the cells was estimated. Cells were harvested when between $80 \%-90 \%$ confluency. $0.25 \%$ Trypsin and DMEM media were warmed to room temperature in a water bath. The source flask was held upside down and tiled so that the cap faced upwards. The cap was unscrewed and the media was aspirated from the corner it was in (not a corner cells had grown on). Touching the sides of the flask the cells grew on was 
avoided. The flask was washed with $3 \mathrm{~mL}$ PBS (10 mL flask) or $10 \mathrm{~mL}$ PBS (25 mL flask) before the PBS was aspirated using the stated technique. $3 \mathrm{~mL}(10 \mathrm{~mL}$ flask) or $10 \mathrm{~mL}$ (25 mL flask) of $0.25 \%$ Trypsin-EDTA was added to the flask. If the cells were to be used in spheroid production immediately, $0.05 \%$ Trypsin-EDTA was used instead, as per the spheroid protocols our lab uses. The cells were incubated at $37^{\circ} \mathrm{C}$ for 1 minutes ( $0.25 \%$ trypsin) or 3 minutes $(0.05 \%$ trypsin). The side of the flask was tapped vigorously to shake the cells loose and the flask was placed under a microscope. If some of the cells were not moving, the flask was tapped more. If, after two rounds of tapping, some cells still remained immobile, the flask was incubated for an additional minute before being tapped again. The trypsin was neutralized with $3 \mathrm{~mL}$ of DMEM for $10 \mathrm{~mL}$ flasks (the $25 \mathrm{~mL}$ flasks did not require neutralization before transfer). A cell count was performed if required. $\mathrm{X} \mathrm{mL}$ of cells were moved to the new flask and $10-\mathrm{X} \mathrm{mL}$ media was added to the new flask where

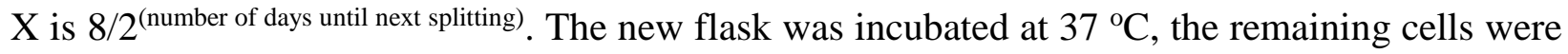
aspirated and the old flask was disposed of in the biological materials waste bin.

\section{Cell Harvest Protocol}

This was performed at a set time following treatment. The media from the cell flask was aspirated and replaced with $500 \mu \mathrm{L}$ of PBS. This PBS was then aspirated and replaced with $300 \mu \mathrm{L}$ of trypsin. The flask was placed in an incubator for 1-2 minutes until the cells detached. The cell/trypsin mixture was pipetted into a $1.5 \mathrm{~mL}$ microcentrifuge tube with $300 \mu \mathrm{L}$ media. The tube was centrifuged at $1500 \mathrm{~g}$ for 5 minutes. A pipette was used to remove $400 \mu \mathrm{L}$ of the supernatant, which was replaced with $200 \mu \mathrm{L}$ of $4 \%$ formaldehyde. The sample was stored at $4^{\circ} \mathrm{C}$ until needed.

\section{Cell Fixing Protocol}

This was performed at a set time following treatment. The media was aspirated and $100 \mu \mathrm{L}$ of PBS was added to each well of the 96 -well plate. $200 \mu \mathrm{L}$ of $4 \%$ formaldehyde was added to each sample before they were stored at $4{ }^{\circ} \mathrm{C}$.

Nanoemulsion Production

Thiol-Maleimide conjugation protocol 
A vacuum was applied to the maleimide lipid solution for 5 minutes. $200 \mu \mathrm{L}$ deprotected AS1411 was added to $800 \mu \mathrm{L}$ maleimide lipid before the solution was stored at $4{ }^{\circ} \mathrm{C}$ overnight.

\section{For Fluorescent Aptamer Deprotection:}

$132 \mu \mathrm{L}$ of $100 \mathrm{mM}$ sodium phosphate buffer, $15 \mu \mathrm{L} 0.05 \mathrm{mM}$ fluorescent aptamer (Cy5-AS1411) and $3 \mu \mathrm{L}$ of $500 \mathrm{mM}$ TCEP were added to a $1.5 \mathrm{~mL}$ centrifuge tube. $132 \mu \mathrm{L}$ of $100 \mathrm{mM}$ sodium phosphate buffer to a $1.5 \mathrm{~mL}$ centrifuge tube. The tube was gently mixed and incubated at room temperature for at least 1 hour. Exposing the fluorescent solutions to light was avoided.

\section{For Non-fluorescent Aptamer Deprotection:}

$172 \mu \mathrm{L}$ of $100 \mathrm{mM}$ sodium phosphate buffer, $20 \mu \mathrm{L}$ of $2 \mathrm{mM}$ AS1411-thiol aptamer, and $8 \mu \mathrm{L}$ of $500 \mathrm{mM}$ TCEP were added to a1.5 $\mathrm{mL}$ centrifuge tube. The tube was gently mixed and incubated at room temperature for at least 1 hour.

\section{Doxorubicin Nanoemulsion Production}

$80 \mu \mathrm{L}$ PFC and $5.8 \mu \mathrm{L}$ of $17.24 \mathrm{mM}$ doxorubicin hydrochloride solution was added to $200 \mu \mathrm{L}$ of lipid solution (final concentration of doxorubicin was $500 \mu \mathrm{M}$ in lipid) in a $15 \mathrm{~mL}$ tube. The tube was sonicated on ice at standard settings ( $60 \%$ amplitude, 5 cycles of 20 seconds on and 40 seconds off). The droplets were washed with centrifugation (2000g for 3 minutes at room temperature). The supernatant was removed and the pellet was re-suspended in $1 \mathrm{~mL}$ of PBS. The nanoemulsions were extruded through $200 \mathrm{~nm}$ membranes seven time and the final solution was stored in a 1.5 $\mathrm{mL}$ centrifuge tube.

\section{Empty Nanoemulsion Production}

$80 \mu \mathrm{L}$ PFC and $5.8 \mu \mathrm{L}$ PBS were added to $200 \mu \mathrm{L}$ of lipid solution in a $15 \mathrm{~mL}$ centrifuge tube. The tube was sonicated on ice at standard settings (60\% amplitude for 5 cycles of 20 seconds on, 40 seconds off). The droplet emulsion was washed via centrifugation at $200 \mathrm{~g}$ for 3 minutes in room temperature. The supernatant was removed and the pellet was resuspended in $1 \mathrm{~mL}$ PBS. The solution was extruded through $200 \mathrm{~nm}$ membranes 7 times. The final solution was stored in a 1.5 $\mathrm{mL}$ centrifuge tube. 


\section{Ultrasound Testing}

Fluorescent nanoemulsions were produced and applied to both single-layer and spheroid cancer cells. After 1 hour, half of the nanoemulsions were placed under ultrasound treatment for a fixed period of time. A one hour waiting period was chosen to allow for the nanoemulsions to potentially bind to receptors on the spheroid without too much passive uptake into the cells. Both ultrasound-treated and non-ultrasound treated emulsions were then be placed in incubation for an additional 2 days before results were obtained. Some samples were examined via flow cytometry. Other samples were sent through a plate reader for fluorescent reading.

\section{RESULTS AND DISCUSSION OF RESULTS}

1. Spheroid Production:

Spheroids were produced with two methods to determine which was more consistent. The first method involved treating a normal 96-well plate with agar before attempting to grow cells. The second method was to use specially made spheroid plates with round, treated bottoms to prevent cell attachment. Spheroid size and shape were visually examined and photos were taken of both results. The method that produced uniformly sized spheroids with low aspect ratios was used in additional experiments. It was found that the spheroid plates performed better, as their round bottoms and surface treatments encouraged more consistent aggregation. As evidenced by Figure 2 below, there is not a statistical difference between using 10k of cells and 15k of cells. Additionally, there is no statistical difference between using 5 and $50 \mu \mathrm{M}$ of doxorubicin, though there is a difference between Control and every other concentration and $0.5 \mu \mathrm{M}$ and every other concentration when testing the various sized spheroids.

Figures 3 and 4 show the shape of spheroids and how high concentrations of doxorubicin disaggregate them. Figure 5 shows why other experiments were performed after 28 hours of treatment, as the standard deviation for MTT absorbance was consistently smaller with less time. The nanoemulsion data was not normal, so ANOVA could not be performed, but they do show that for liquid doxorubicin the control group and $5 \mu \mathrm{M}$ liquid doxotubicin group there is no statistical difference in absorbance, but there is a difference between each of $50 \mu \mathrm{M}$ and $25 \mu \mathrm{M}$ and the others. 


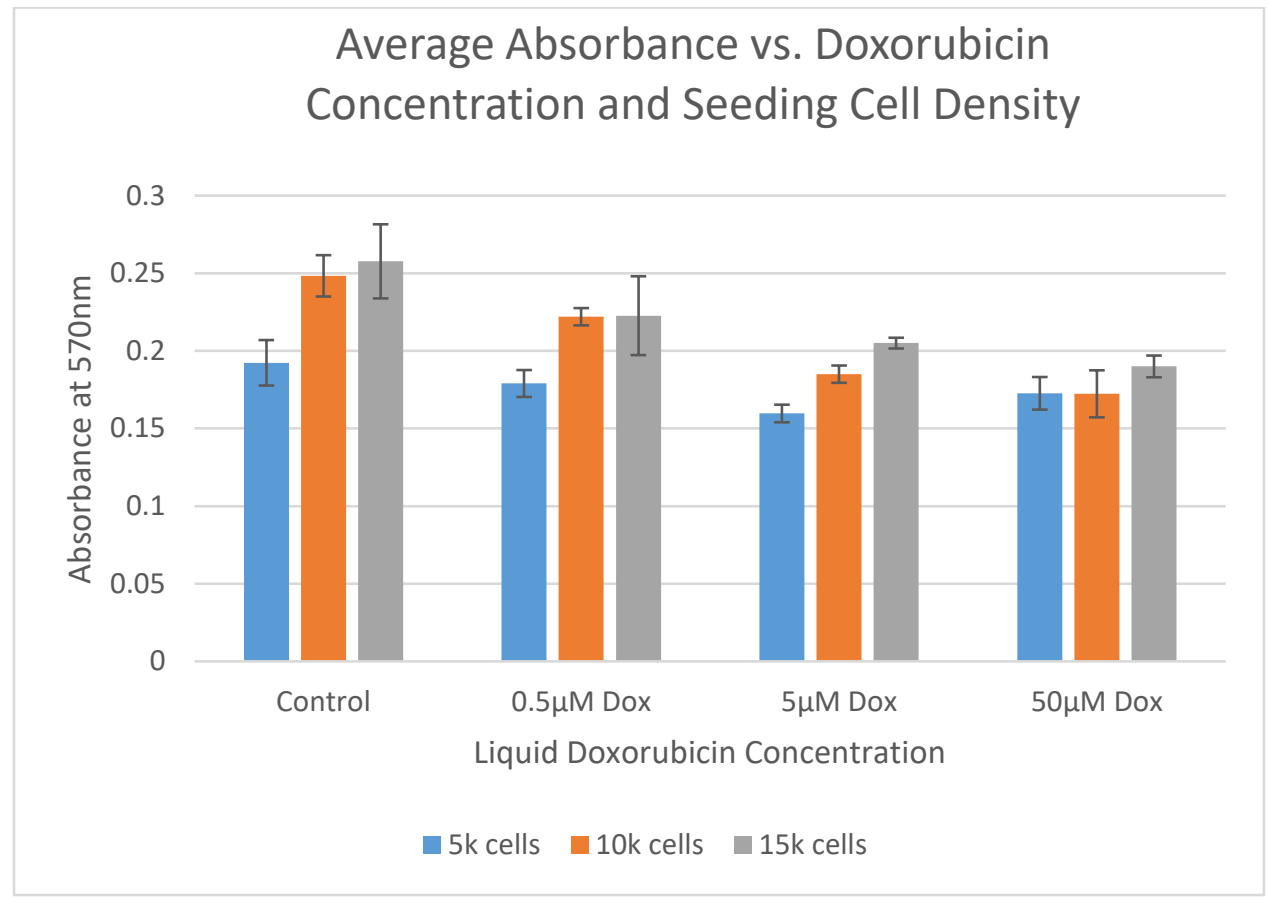

Figure 1: MTT absorbance vs. doxorubicin concentration and seeding cell density

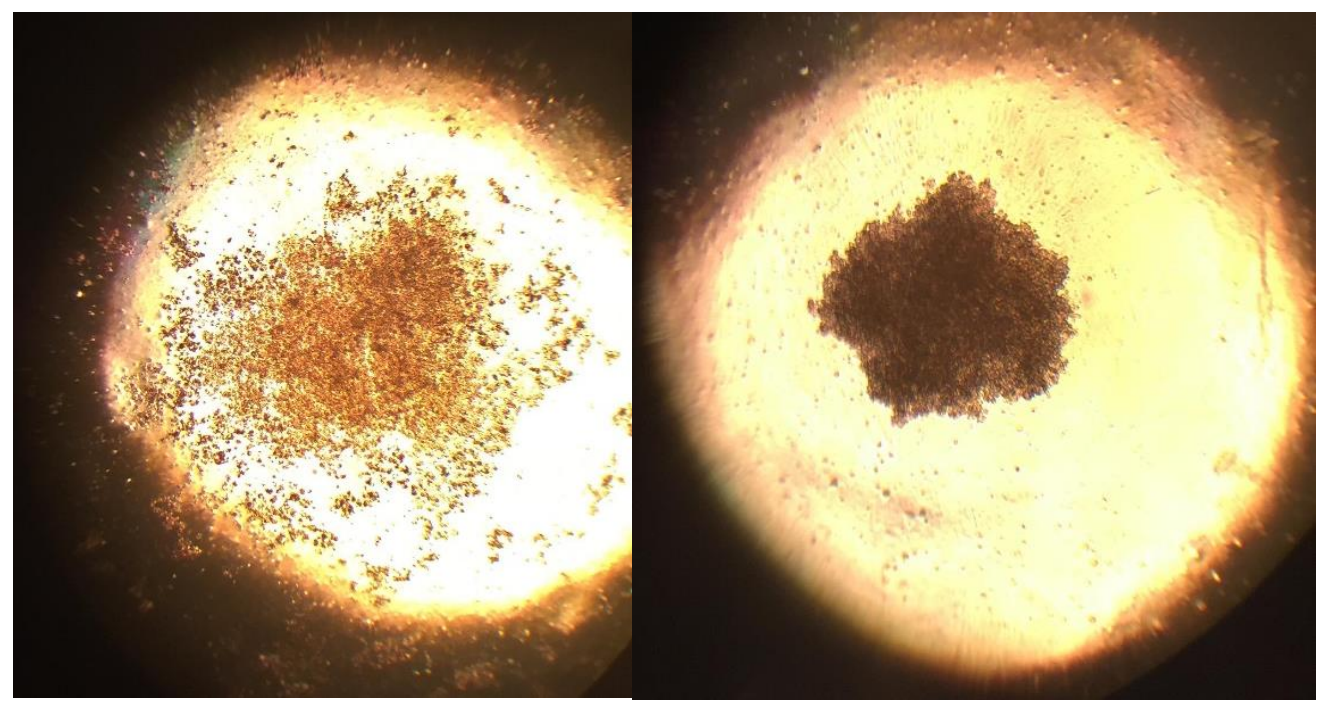

Figure 2: $15 \mathrm{k}$ seeded spheroid after 5 days of growth and $50 \mu \mathrm{M}$ doxorubicin (left) and a 15k seeded spheroid after 5 days of growth and no doxorubicin treatment (right) (spheroid plate, cropped) 


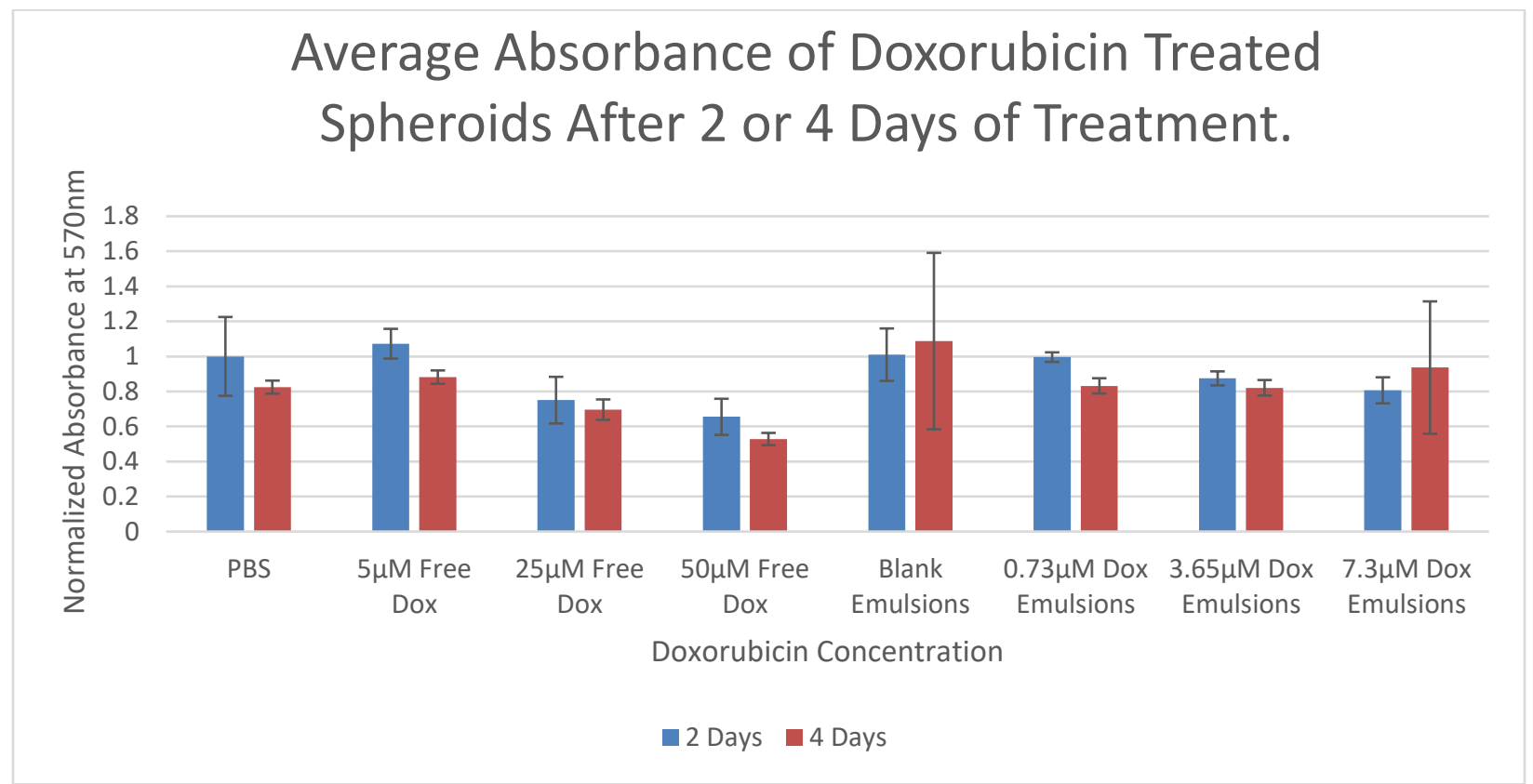

Figure 3: Absorbance of MTT treated spheroids following doxorubicin treatments at different times

\section{Nanoemulsion Testing}

Doxorubicin nanoemulsions were produced and placed into 5 wells of a clean 96 well plate, with $100 \mu \mathrm{L}$ per well. Three wells were also filled with each of the following: $0.58 \%$ doxorubicin (the total concentration of doxorubicin in the nanoemulsion if all the doxorubicin used entered the nanoemulsions, or the theoretical loading) $0.058 \%$ doxorubicin, $5.8 \times 10^{-3} \%$ doxorubicin, $5.8 \times 10^{-4} \%$ doxorubicin, and $5.8 \times 10^{-5} \%$ doxorubicin. $100 \mu \mathrm{L}$ was used here as well. Then each well received $100 \mu \mathrm{L}$ of $4 \%$ methanol, which ruptured the nanoemulsions and allowed the doxorubicin to be released into solution. Since each sample had the same amount of methanol, a methanol background test was not necessary as any background reading would be the same for each sample. The fluorescence of the doxorubicin was read via a plate reader, and the concentration of doxorubicin in the nanoemulsions was estimated to be $14.6 \%$ of the maximum value, calculated from a polynomial curve that fits the data down to $5.8 \times 10^{-5} \%$ doxorubicin within the linear range of the polynomial curve, which results in a value of $0.08468 \%$ or $14.60 \mu \mathrm{M}$. This loading 
efficiency was used in interpreting all nanoemulsion data in this paper as they were produced under the same conditions as all of the batches. .

The size of the nanoemulsions was determined by diluting 12-day-old doxorubicin nanoemulsions in water and placing the solution in a NanoBrook ZetaPALS potential analyzer. The sample was scanned with a $658 \mathrm{~nm}$ laser and the scattering within indicated the range of sizes for the nanoemulsions. The effective diameter was measured to be 703 $\mathrm{nm}$, which may have weakened penetration and thus effecasy but smaller nanoemulsions could be created using smaller filters.

Additionally, the integrity lifespan of the nanoemulsions was tested by measuring the fluorescence of flat cells treated with FITC and AS1411/Cy5 FITC nanoemulsions which had been stored for up to 2 weeks after production. The FITC nanoemulsions contained FITC liquid while the AS1411/Cy5 FITC nanoemulsions contained FITC liquid and had AS1411/Cy5 bound to the membrane. The effectiveness of these nanoemulsions was determined by counting the cells that contained FITC or Cy5 after treatment and fixing to show how many cells would receive treatment with chemotherapeutic nanoemulsions. The results of this study are seen in Figure 6, with the controls being no treatment. The results show no difference between one day and one week as each is within one standard deviation of the other. After two weeks, significant leaking of the FITC was seen and fewer cells were marked when total cell association was tested after washing.

Doxorubicin was used for the drug tests due to its chemotherapeutic properties. Doxorubicin has an IC50 Z-Score of 1.16291 on MDA-MB-231. A Z-Score of 2 or above indicates the cell line is resistant to the drug while a Z-Score of -2 or below indicates it is sensitive to the drug (Cancer RxGenes). The effect of doxorubicin on these cells has also been shown experimentally in our lab during a previous experiment. In Figure 6, the percent viability of flat MDA-MB-231 cells can be seen decreasing as doxorubicin concentration increases. 


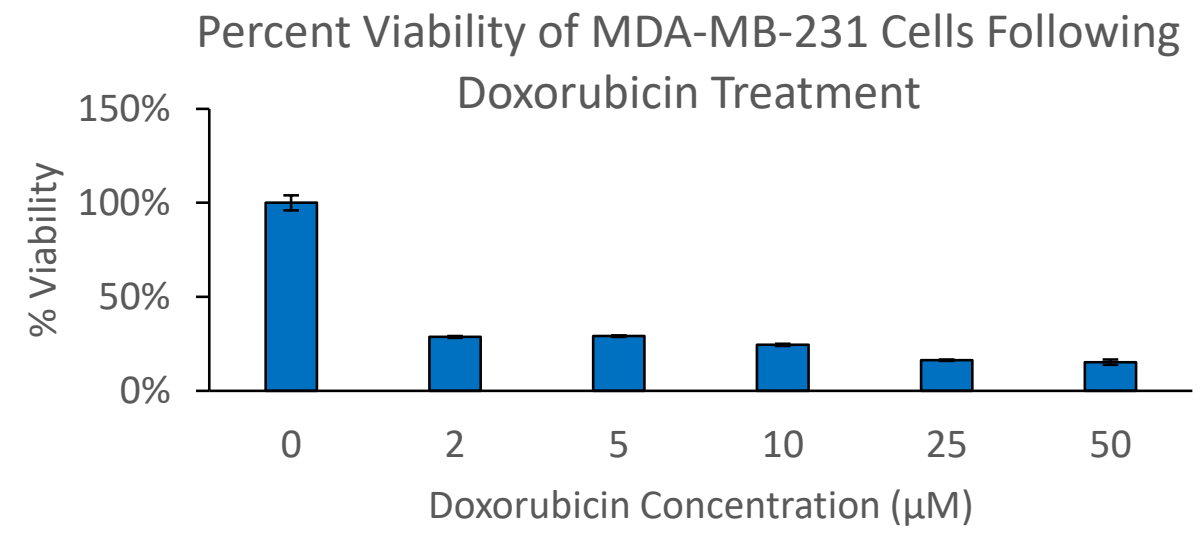

Figure 6: Percent Viability of MDA-MB-231 Cells Following Doxorubicin Treatment

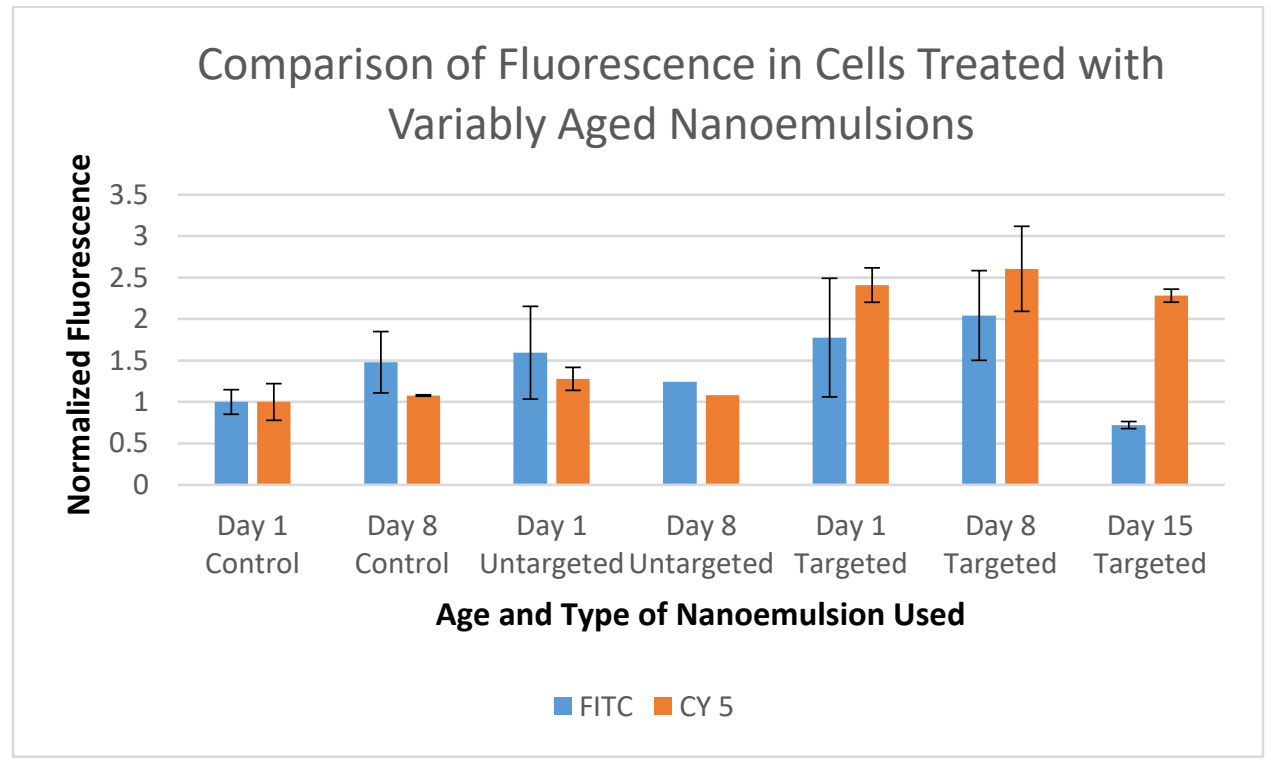

Figure 6: Weekly fluorescence test to determine nanoemulsion lifespan through treatment of flat cells.

\section{AS1411 Testing (Fluorescent)}

AS1411 and non-AS1411 fluorescent nanoemulsions were produced and applied to both single layer and spheroid cancer cells. The cells were then be returned to incubation for 2 days before being examined. Some samples were examined via flow cytometry. Other samples were sent through a plate reader for fluorescent reading. It was expected that the AS1411 nanoemulsions would result in more fluorescence within the cells as they bind to nucleolin. However, since there only tumor cells were tested, the effect may not be 
noticeable, as AS1411 is used to cause the nanoemulsions to specifically target cancer tissue instead of healthy tissue.

4. AS1411 Testing (Drug)

AS1411 and non-AS1411 modified doxorubicin-loaded nanoemulsions were produced and applied to both single-layer cancer cells and spheroids. After two days of exposure in incubation, results were obtained. To measure cell viability, some sets were tested with an MTT assay after 2 days of growth. This two day waiting time was chosen based on the results of an experiment seen in Figure 5, as two days resulted in less variance than four days. It was expected that the AS1411 nanoemulsions would result in less cell viability, but this may be less noticeable for the reasons mentioned above as no non-cancer controls were used. As Figures 6 and 7 show below, there are inconsistent differences between the AS1411-targeted and untargeted nanoemulsions, with large standard deviations within some samples. An ANOVA for Figure 6 shows that both emulsion concentration and doxorubicin presence have statistically significant effects on the absorbance, but AS1411 does not. AS1411 combined with emulsion concentration is shown to be statistically significant, but the results are clearly influenced by what are likely outliers, as the presence of AS1411 is shown to worsen the effect of some nanoemulsion concentrations. An ANOVA of Figure 7 could not be performed due to low R-Squared value (50.39\%) found through Minitab. The background reading from blank nanoemulsions were not subtracted from the values as the presence of nanoemulsions weakened absorbance as seen between the No Emulsion and Drugless groups. 


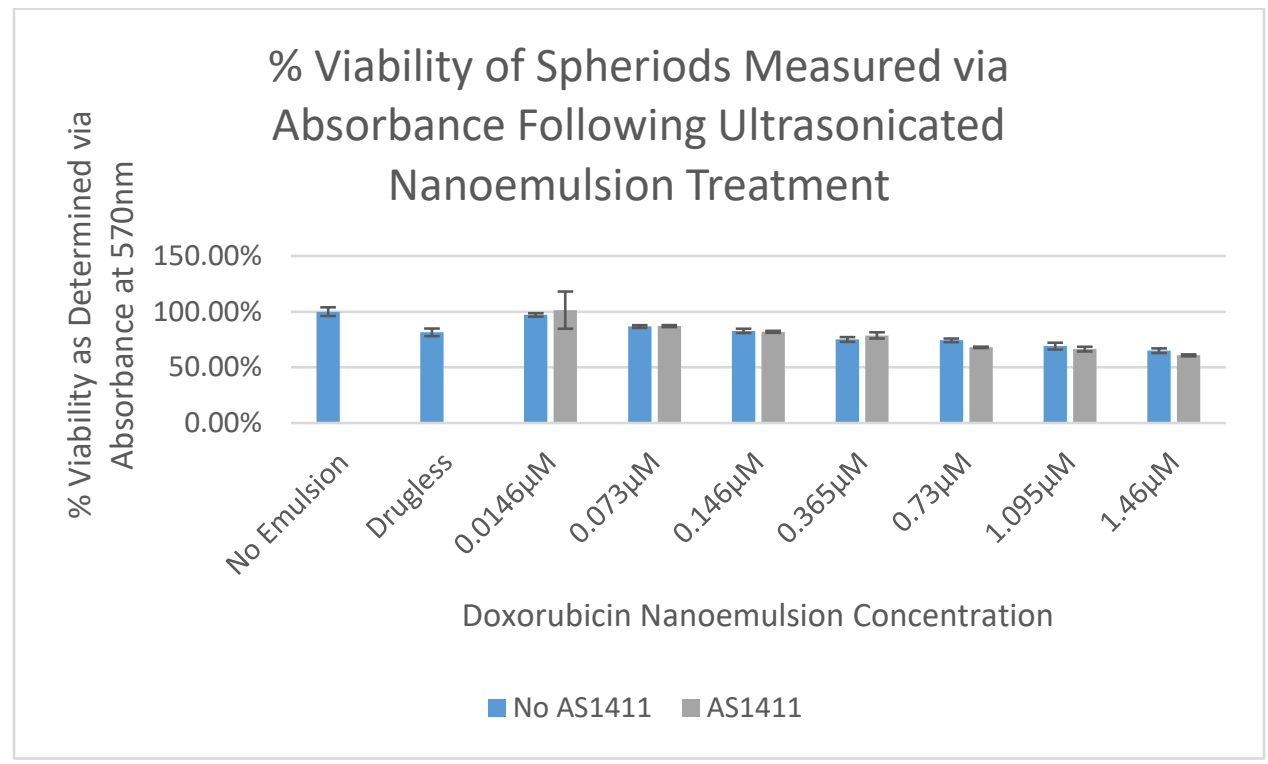

Figure 7: Percent Viability determined via plate reading for MTT treated (2 hour incubation) spheroids treated with doxorubicin nanoemulsions and ultrasound.

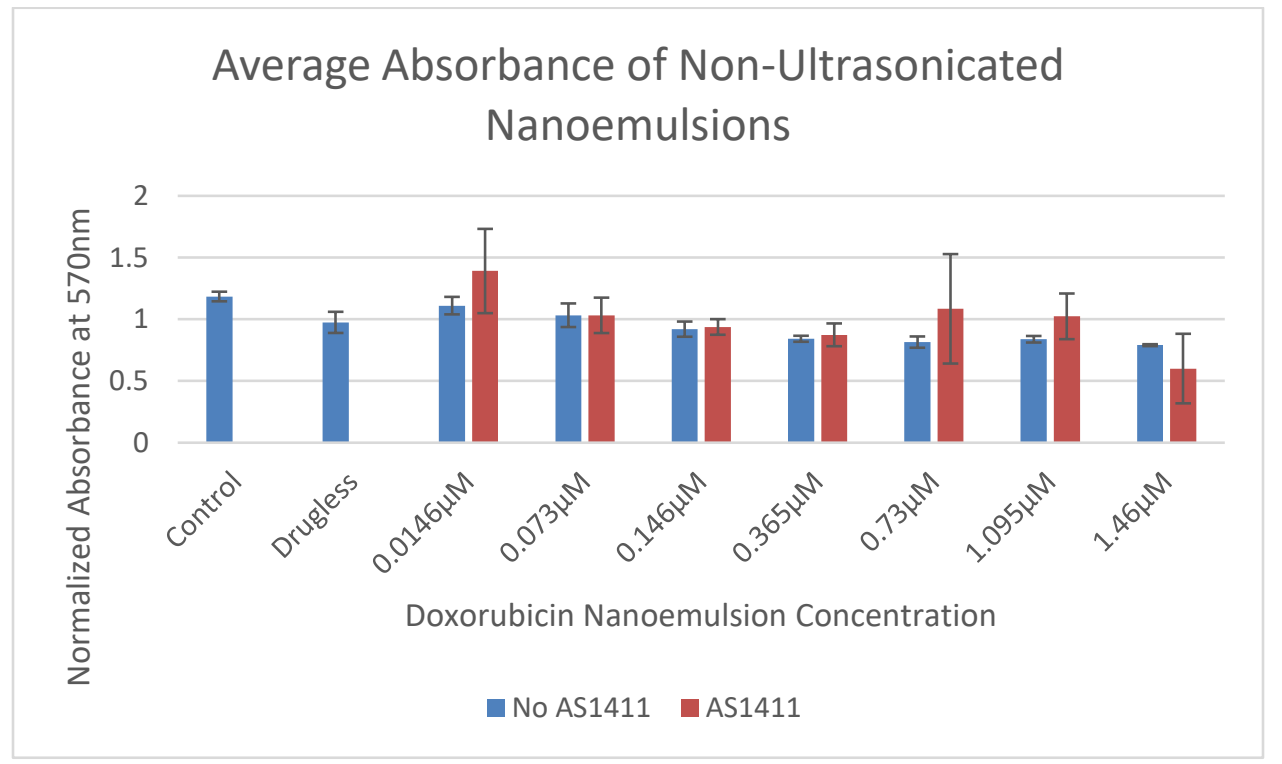

Figure 8: Average plate reading for MTT treated (2 hour incubation) spheroids treated with un-sonicated doxorubicin nanoemulsions. 


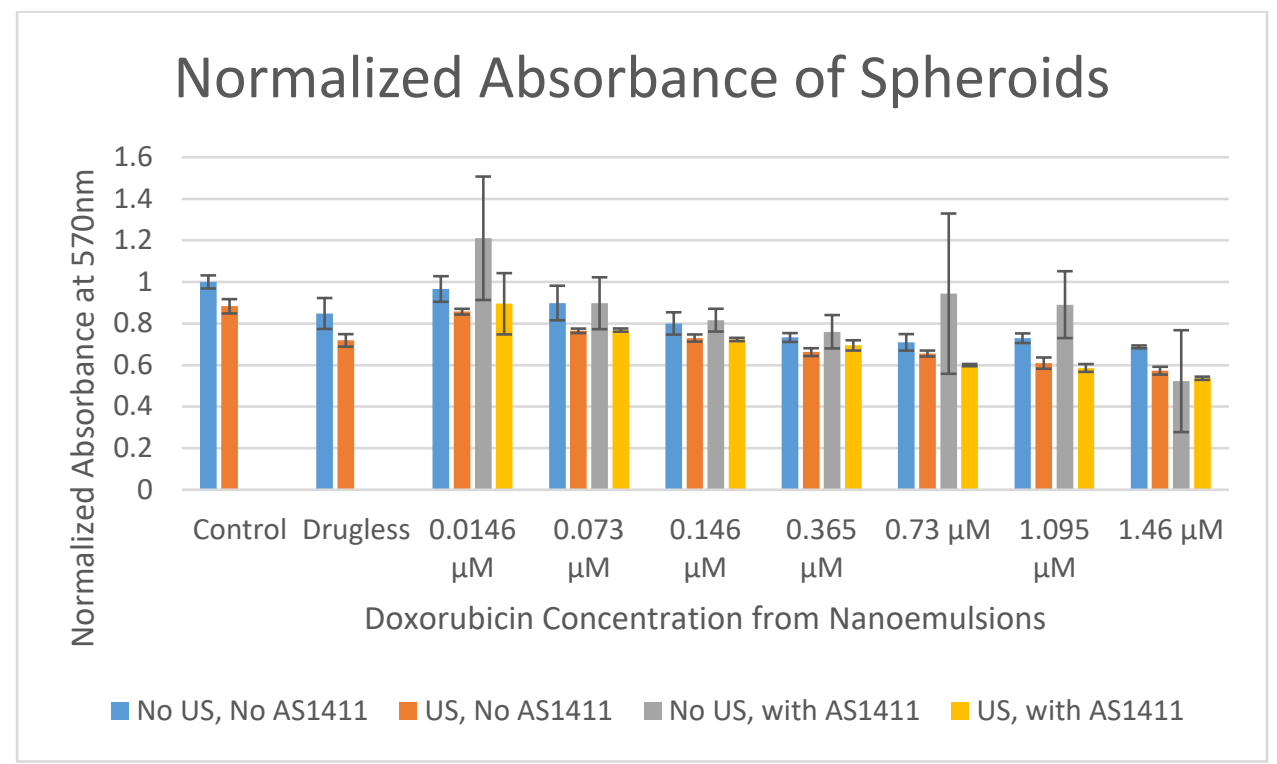

Figure10: The combined data from Figure 8 and 9. The normalized values of the absorbance from spheroids

1. Ultrasound Testing (Fluorescent)

It was expected that the ultrasound-treated spheroids would have absorbed more of the fluorescent material, resulting in a higher flow cytometry reading as the fluorescent molecules were delivered into the cell, and a lower pate reading as less MTT was converted due to greater cytotoxicity.

\section{Ultrasound Testing (Drug)}

Doxorubicin-loaded nanoemulsions were produced and applied to both single-layer and spheroid cancer cells. After 1 hour, half of the nanoemulsions were placed under ultrasound for a fixed period of time. Both ultrasound-treated and non-ultrasound treated emulsions were then placed in incubation for an additional 2 days before results were obtained. To measure cell viability an MTT assay was applied to some sets, the results of which are seen in Figure 8. Here, both nanoemulsions and liquid doxorubicin were tested with and without ultrasound. ANOVA could not be performed due to a low r-squared value of $38.82 \%$. It was expected that the ultrasound-treated spheroids would be less viable compared to untreated spheroids. The liquid doxorubicin ANOVA for Figure 9 showed that the doxorubicin concentration had some effect on absorbance, but ultrasound did not, which was expected without nanoemulsions. Figures 9 and 10 confirms this by comparing treatments of liquid doxorubicin with and without ultrasound, although the data was too 
far from a normal distribution to perform an ANOVA. Figure 10 shows an unexpected increase in absorbance as doxorubicin concentration increases, but this may be due to doxorubicin being a similar color to the product of MTT assays, resulting in false positives. Since the goal of this experiment was to determine the effects of ultrasound and the samples are compared against those treated with the same amount of doxorubicin, this does not change the conclusion.

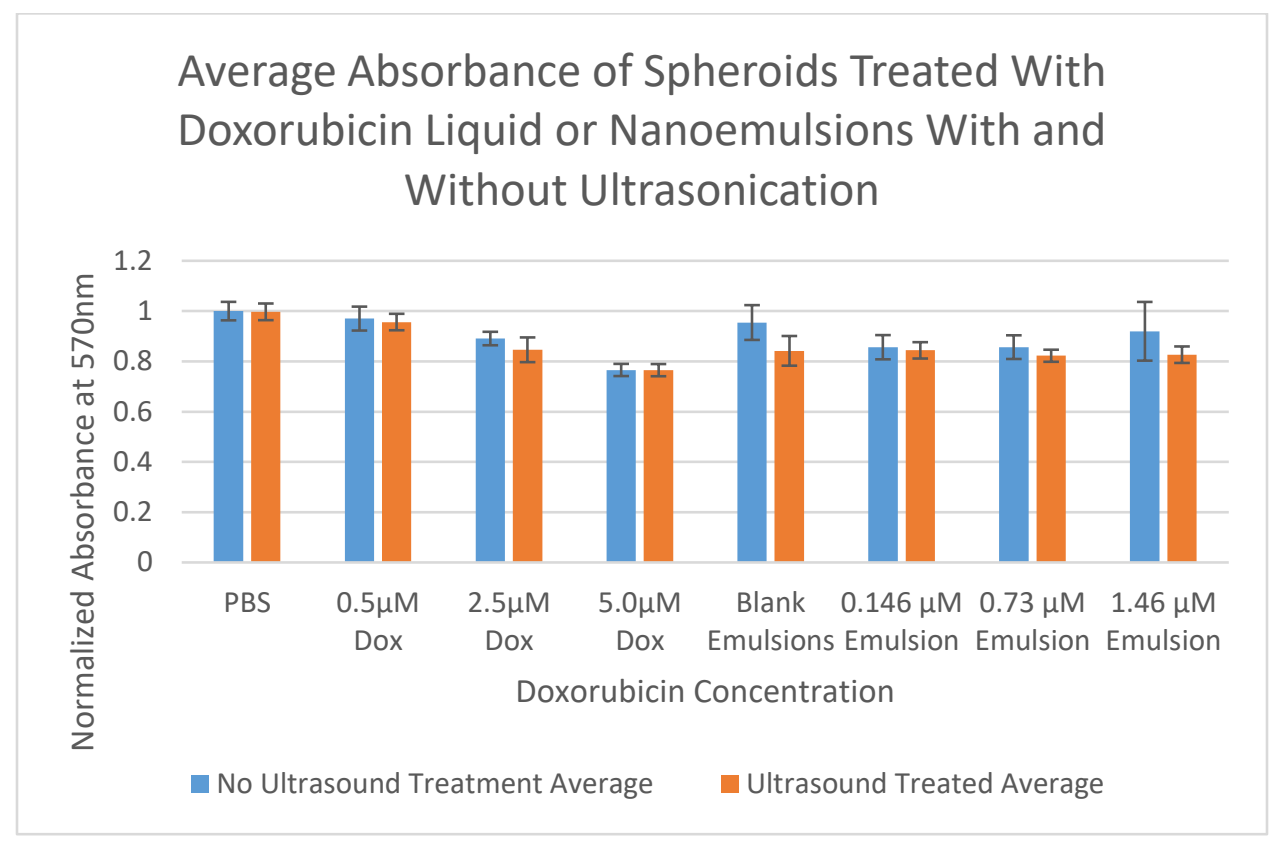

Figure 9: Absorbance of MTT treated spheroids following doxorubicin treatment. Each emulsion sample contained 10 $\mu \mathrm{L}$ of nanoemulsions, with the percentage indicating the amount that contained doxorubicin. Ultrasound occurred 30 minutes following nanoemulsion place 


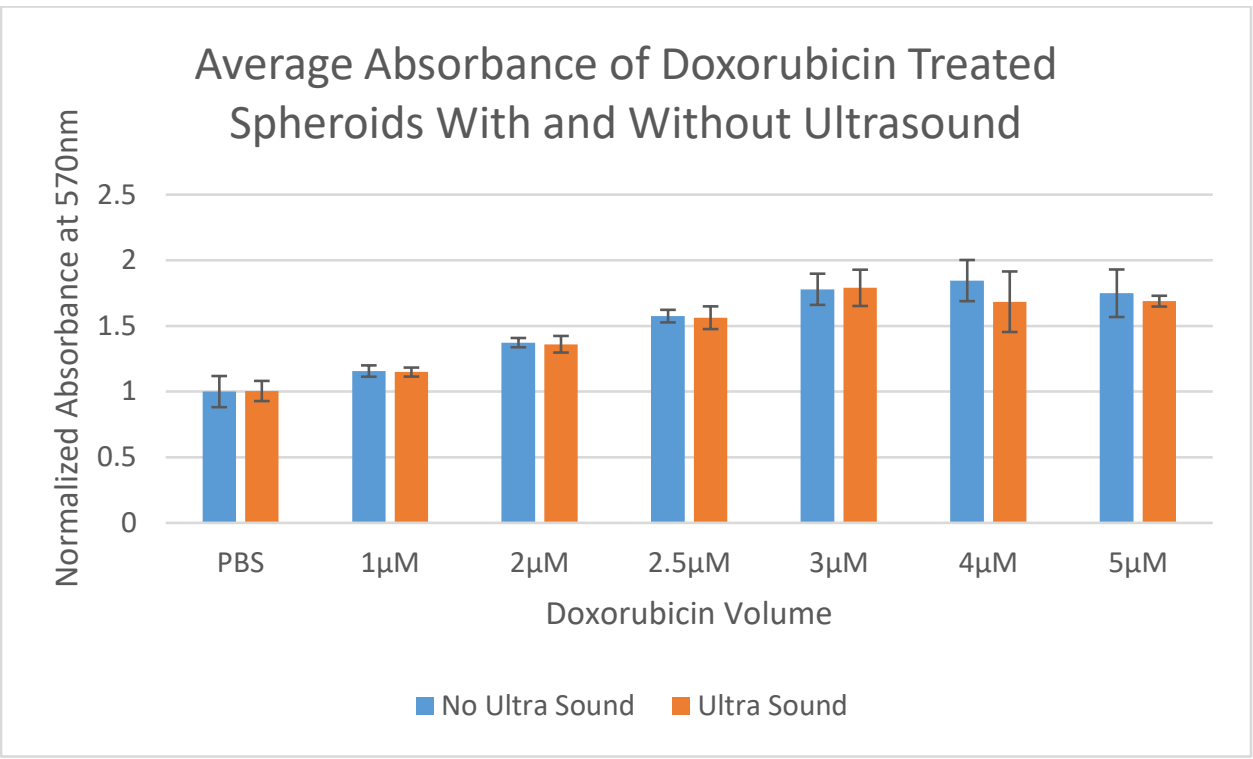

Figure 10: Absorbance of MTT treated spheroids following liquid doxorubicin treatment

\section{Combined Testing (Fluorescent)}

AS1411 and non-AS1411 conjugated fluorescent nanoemulsions were produced and applied to both single-layer cancer cells and spheroids. After 1 hour, half of each type was placed under ultrasound for a fixed period of time. Then, all samples were returned to incubation for 2 days. For each sample type half of the wells were examined via flow cytometry while the other half were examined in a plate reader. It was expected that the AS1411/ultrasound cells would have the most fluorescence. The next most fluorescent would be ultrasound, followed by AS1411, as AS1411 is expected to less of a noticeable effect without noncancer cells to differentiate cancer from. Finally, the control is expected to have the least fluorescence. We can see in Figure 11 below that the ultrasound-treated cells had consistently lower fluorescence intensity than the non-ultrasound treated cells and that AS1411 improved the cell counts. Figure 11 was normalized to the untargeted, nonultrasonicated samples as untreated samples were not used in this experiment. A similar experiment that shows how these treatments compare to a control can be seen in Figure 7. This can be explained as the ultrasonication creating holes in the cells allowing for the FITC to escape. Testing this on spheroids, as seen in Figure 12, shows less effect. The FITC intensity could not be tested in ANOVA due to a low R-squared value, while the Cy5 
intensity showed only the presence of Cy5/AS1411 and the combination of that presence with ultrasound to be significant. Specifically, the presence of Cy5/AS1411 increased the intensity while adding ultrasound to Cy5/AS1411 treated cells lowered it. The severe differences between Figures 11 and 12 are likely due to the use of flat cells in Figure 11 and spheroids in Figure 12 or the immediate fixing of the cells in Figure 12's experiments.

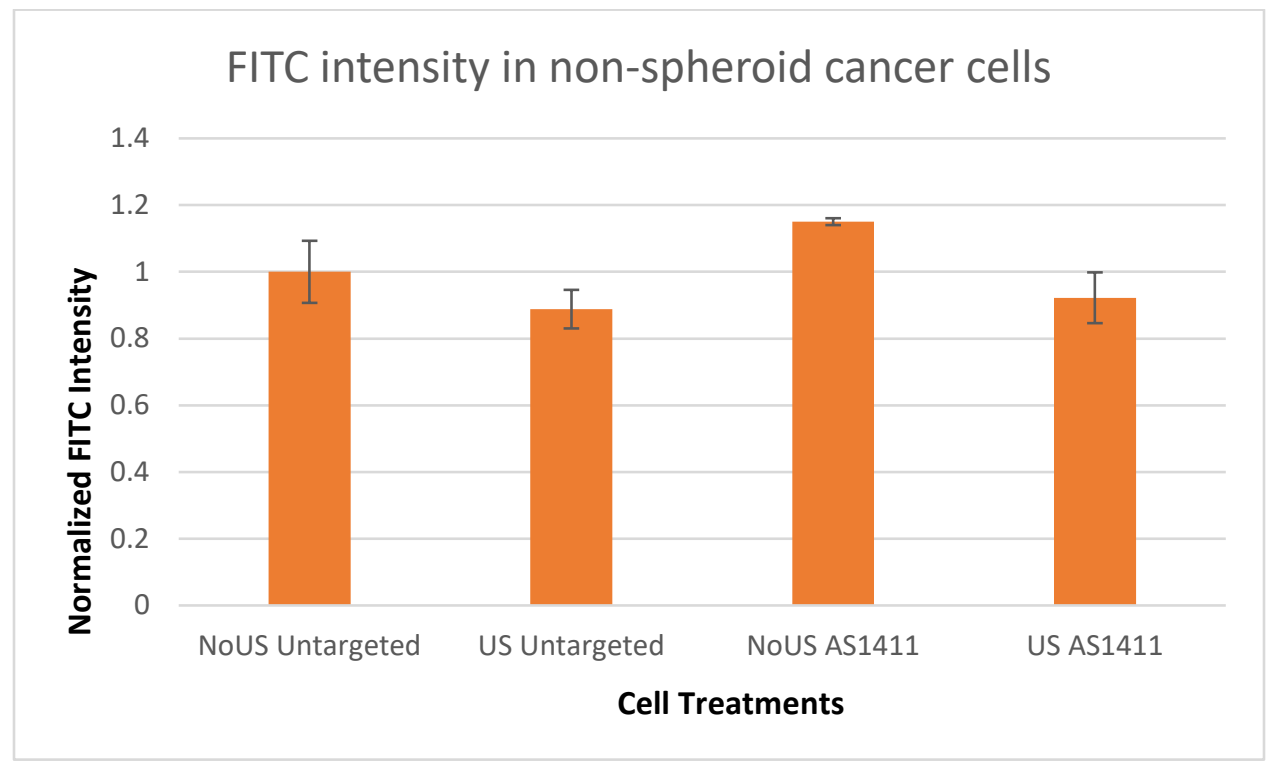

Figure 11: Normalized values from Total Cell Association Flow Cytometry MACS Quantity Analyzer reading of FITC in flat cells after various treatments for 1 hour. (1=3341.7 cells)

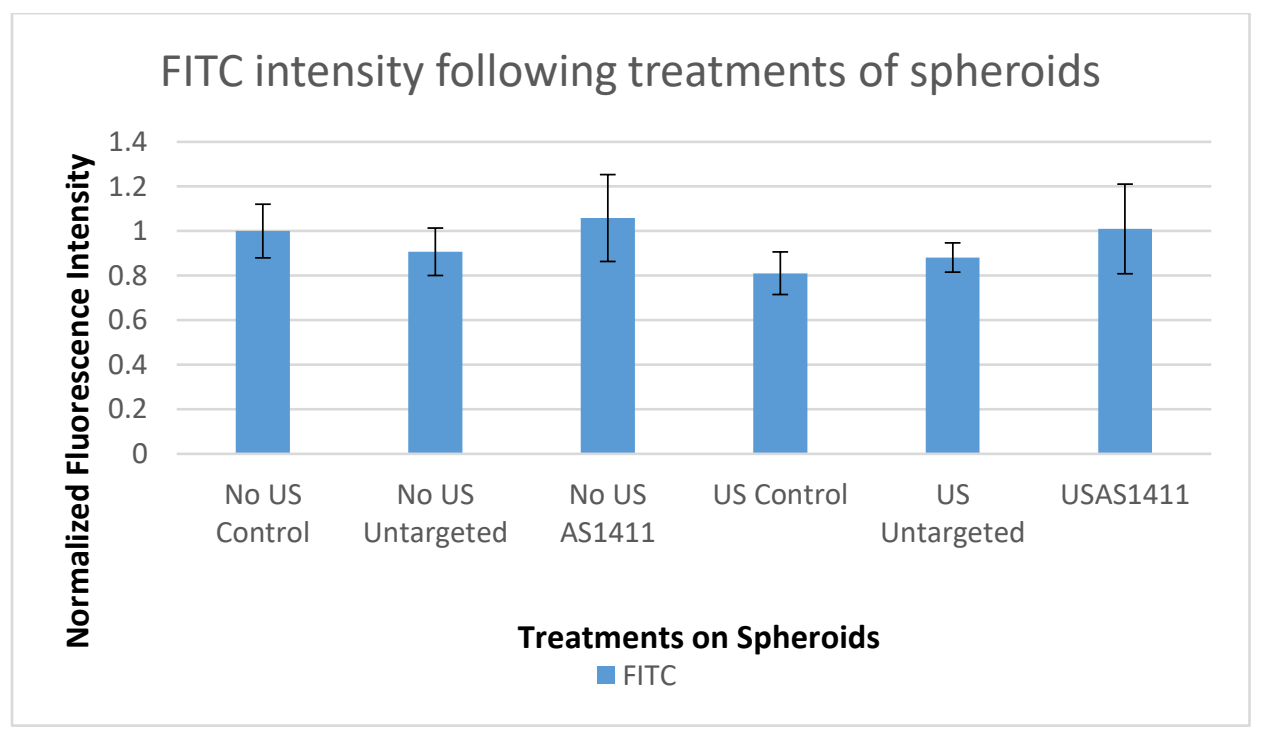

Figure 12: A normalized graph showing the cells counted via Total Cell Association Flow Cytometry MACS Quantity Analyzer containing FITC or Cy5 immediately following ultrasound treatment of spheroids ( $1=158.5$ cells) 


\section{Combined Testing (Drug)}

AS1411 and non-AS1411 conjugated doxorubicin nanoemulsions were produced and applied to both single-layer cells and spheroids. After 1 hour, half of each type were placed under ultrasound before each sample was returned to incubate for 2 days. Samples were treated under an MTT assay to measure viability. It was expected that the AS1411/ultrasound cells would have the most fluorescence. The next most fluorescent would be ultrasound, followed by AS1411. Finally, the control is expected to have the least fluorescence.

Figure 13 shows the average absorbance from MTT assays of spheroids after nanoemulsion treatments. Some values have large standard deviations or are simply abnormally large. Unfortunately, no cause for these abnormalities have been found. Additional testing may find these to be outliers. Additionally, ANOVA could not be performed, as the residual tests were failed as seen in Figure 14. Specifically, the normal probability plot deviated from the center line drastically and the versus fit is drastically large on the right side.

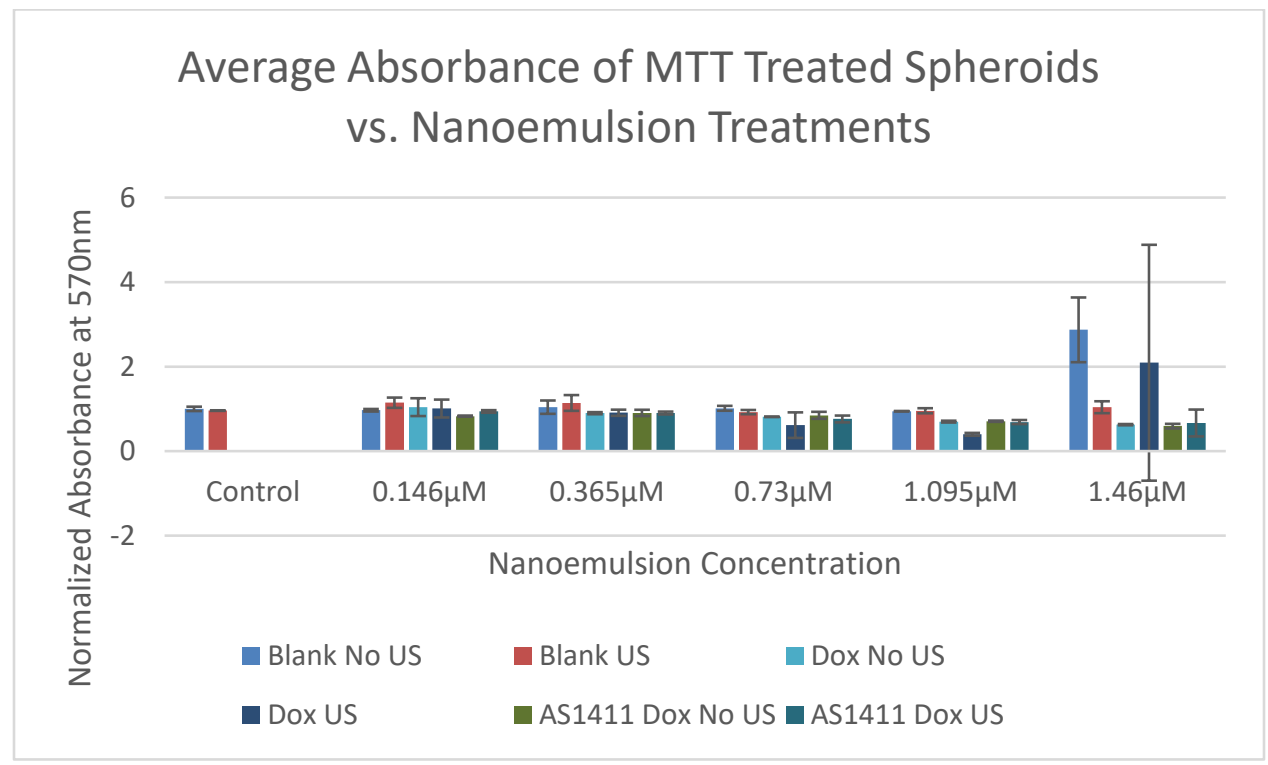

Figure 13: Absorbance of MTT in spheroids following nanoemulsion treatments. The number of blank nanoemulsions in each group is equal to the amount of nanoemulsions at that concentration of doxorubicin for drug emulsions. 


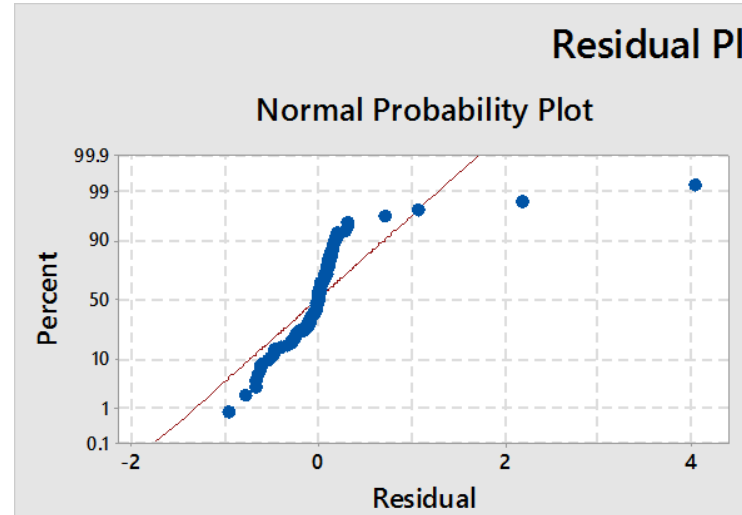

\section{Plots for Value}
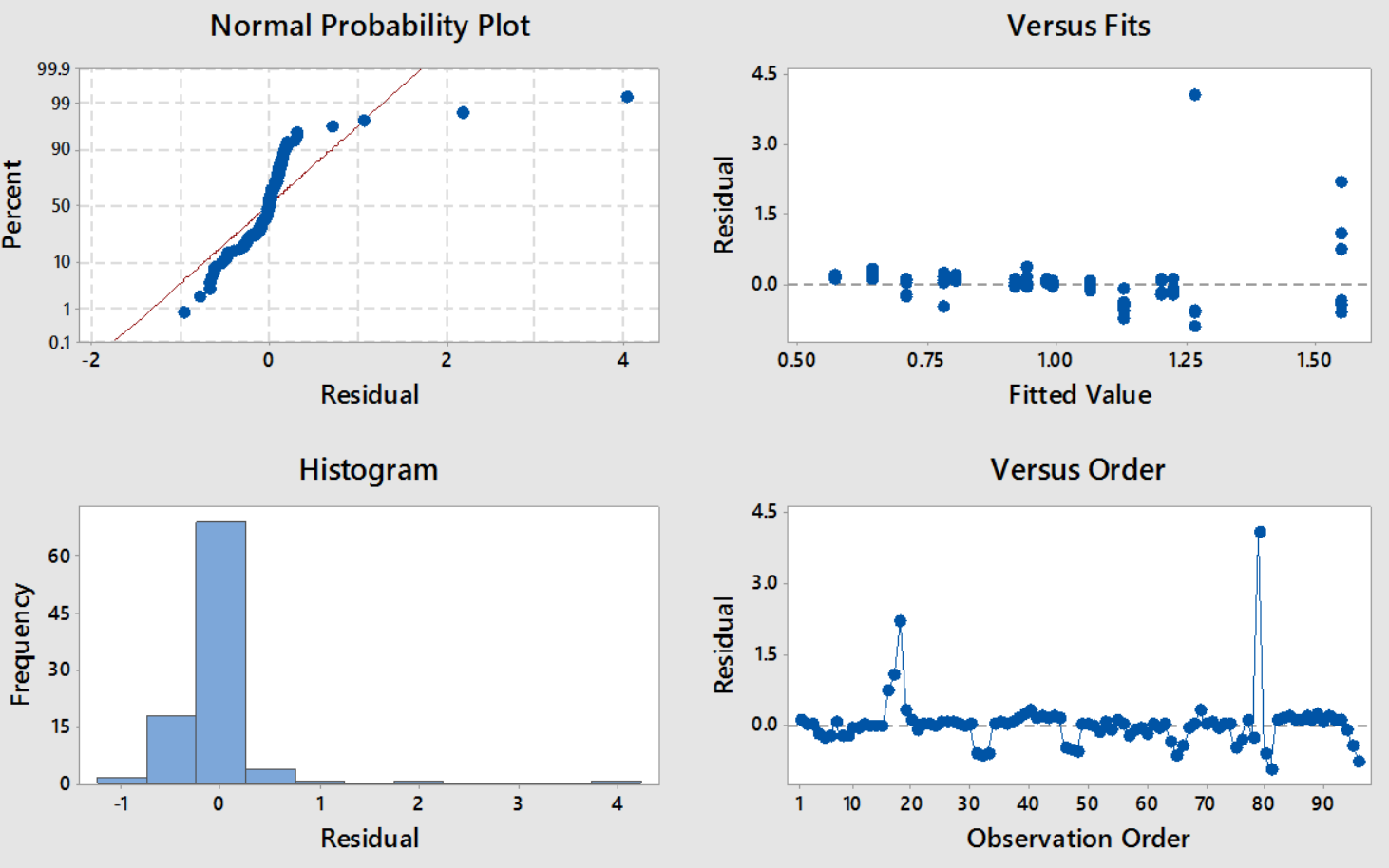

Figure 14: Residual Plots for the combined tests

\section{CONCLUSIONS}

Cancer continues to be a major source of mortality worldwide. This paper has presented a plan to test two methods of localizing drug delivery in nanoemulsions. Combined, these methods may result in fewer side effects for current and future cancer patients. AS1411 surface modification has the potential to result in greater uptake into cancer cells specifically and greater accumulation around the tumor. Ultrasound-induced vaporization of nanoemulsions has the potential to increase penetration into the spheroid and increase drug uptake. Neither of these methods should affect healthy tissue, although the ultrasound is area specific and could injure healthy tissue adjacent to the tumor. The use of spheroids should result in more accurate comparisons to in vivo conditions. 


\section{RECOMMENDATIONS}

The results of this study leave many areas for future research. While the combined effects of AS1411 and ultrasonication showed little increase compared to ultrasonication alone, this study was limited by the use of only cancerous cells. Future studies can experiment using cancerous spheroids and healthy tissue to see if AS1411 will encourage drug delivery to cancerous cells over

healthy cells. Similarly, this experiment could be performed with an artificial circulatory system to see if the AS1411 will hold the nanoemulsions to the spheroids long enough for a high concentration to build up there so that only a short period of ultrasonication is necessary for treatment. If AS1411 is shown to contribute to the selectivity of the drug's effects, in vivo testing in animals may be warranted. This study has yielded initial results on ultrasound's ability to improve drug delivery in tumors in vivo and has revealed potential complications to avoid when testing the effects of AS1411 on nanoemulsions. Additional studies may include testing other chemicals to target cancer besides AS1411 and see how they influence uptake with ultrasound.

There is some concern that the physical structures of spheroids prevent MTT from reaching cells in the center, skewing cell viability results. This was not anticipated in this paper and was not accounted for, which may have resulted in the effects of the drugs being stronger than recorded here. Future tests should involve a step disaggregating the spheroid without harming the cells prior to MTT application. Other studies have used the CellTiter-Glo Luminescent Assay to disaggregate the spheroids through lysis and determine the relative number of viable cells prior to lysing using the ATP that was in the cells. There was also concerns that doxorubicin could interfere with the absorbance of the crystals from the MTT assay. An absorbance test was performed, and while doxorubicin does show some absorbance at 570nm, it is very minor, with its peak absorbance being between 480 and $490 \mathrm{~nm}$. Concerns were also raised that doxorubicin may be too easy of a drug to enter cells, thus negating some of the effects of the drug delivery mechanisms. Due to these concerns, it is suggested that future studies consider using other drugs to determine if these concerns are valid.

Additional concerns are that the ultrasonication of nanoemulsions could induce metastasis by breaking cells off the tumor and that the large nanoemulsions may impede uptake into 
spheroids. Future tests could verify the first concern by using MTT to test the viability of cells that break off from the spheroid during ultrasound treatment. Further testing with smaller nanoemulsions can test the effect of the second concern. 


\section{BIBLIOGRAPHY}

Bates, Paula J, et al. "G-Quadruplex Oligonucleotide As1411 As a Cancer-Targeting Agent: Uses and Mechanisms." Bba - General Subjects: Part B, vol. 1861, no. 5, 2017, pp. 1414-1428., doi:10.1016/j.bbagen.2016.12.015.

“Cancer." World Health Organization, World Health Organization, www.who.int/mediacentre/factsheets/fs297/en/.

"Cancer Statistics." National Cancer Institute, www.cancer.gov/aboutcancer/understanding/statistics.

"Chemotherapy Side Effects." American Cancer Society, www.cancer.org/treatment/treatmentsand-side-effects/treatment-types/chemotherapy/chemotherapy-side-effects.html.

"Genomics of Drug Sensitivity in Cancer." CancerRxGenes, www.cancerrxgene.org/translation/CellLine/905960.

Ivascu, A., Kubbies, M."Diversity of cell-mediated adhesions in breast cancer spheroids". International Journal of Oncology 31.6 (2007): 1403-1413.

Luo Z, et al. "Precise Glioblastoma Targeting by As1411 Aptamer-Functionalized Poly (1-ГGlutamylglutamine)-Paclitaxel Nanoconjugates." Journal of Colloid and Interface Science, vol. 490, 2017, pp. 783-796., doi:10.1016/j.jcis.2016.12.004.

Muehlmann, Luis Alexandre, et al. "Aluminium-Phthalocyanine Chloride Nanoemulsions for Anticancer Photodynamic Therapy: Development and in Vitro Activity against Monolayers and Spheroids of Human Mammary Adenocarcinoma MCF-7 Cells." Journal of Nanobiotechnology, vol. 13, no. 1, 2015, doi:10.1186/s12951-015-0095-3.

Obrien, W.d., and J.f. Zachary. "Lung Damage Assessment from Exposure to Pulsed-Wave Ultrasound in the Rabbit, Mouse, and Pig." IEEE Transactions on Ultrasonics, Ferroelectrics and Frequency Control, vol. 44, no. 2, Mar. 1997, pp. 473-485., doi:10.1109/58.585132. 
Zhou, Yufeng. "Ultrasound-Mediated Drug/Gene Delivery in Solid Tumor Treatment.” Journal of Healthcare Engineering, vol. 4, no. 2, Dec. 2012, pp. 223-254., doi:10.1260/20402295.4.2.223. 


\section{VITA}

Daniel Hodge received his Bachelor's of Science in Bioengineering with honors from the University of Louisville in 2017. He was a pre-med student and completed the Guaranteed Entrance to Medical School program. While a student, he worked at Evolva as a research laboratory intern in Lexington, KY. He also worked as a medical scribe in Louisville emergency rooms through the company PhysAssist. He worked with Dr. Jill Steinbach-Rankins on researching the production and testing of nanofibers. The work with Dr. Steinbach-Rankins resulted in a publication. Daniel served as the president of the University of Louisville Biomedical Engineering Society. In his research with Dr. Steinbach-Rankins, he also learned how to culture mammalian cells. Currently, Daniel is completing his Masters of Engineering in Bioengineering at the University of Louisville under Dr. Jonathan Kopechek. Daniel has been accepted into the University of Louisville Medical School class of 2022 and will begin attending Fall of 2018. 